\title{
New technique for fabrication of high frequency piezoelectric Micromachined Ultrasound Transducers
}

\author{
Pedersen, T; Thomsen, Erik Vilain; Zawada, T; Hansen, K; Lou-Møller, R
}

Published in:

IEEE Ultrasonics Symposium, 2008. IUS 2008.

Link to article, DOI:

10.1109/ULTSYM.2008.0523

Publication date:

2008

Document Version

Publisher's PDF, also known as Version of record

Link back to DTU Orbit

Citation $(A P A)$ :

Pedersen, T., Thomsen, E. V., Zawada, T., Hansen, K., \& Lou-Møller, R. (2008). New technique for fabrication of high frequency piezoelectric Micromachined Ultrasound Transducers. In IEEE Ultrasonics Symposium, 2008. IUS 2008. IEEE. https://doi.org/10.1109/ULTSYM.2008.0523

\section{General rights}

Copyright and moral rights for the publications made accessible in the public portal are retained by the authors and/or other copyright owners and it is a condition of accessing publications that users recognise and abide by the legal requirements associated with these rights.

- Users may download and print one copy of any publication from the public portal for the purpose of private study or research.

- You may not further distribute the material or use it for any profit-making activity or commercial gain

- You may freely distribute the URL identifying the publication in the public portal 


\section{New Technique for Fabrication of High Frequency Piezoelectric Micromachined Ultrasound Transducers}

\author{
T. Pedersen, E.V. Thomsen \\ Department of Micro and Nanotechnology \\ Technical University of Denmark \\ Kgs. Lyngby, Denmark \\ Email: thope@nanotech.dtu.dk
}

\author{
T. Zawada, K. Hansen \\ InSensor $\mathrm{A} / \mathrm{S}$ \\ Kvistgaard, Denmark
}

\author{
R. Lou-Moeller \\ Ferroperm Piezoceramcis A/S \\ Kvistgaard, Denmark
}

\begin{abstract}
A novel technique for fabrication of linear arrays of high frequency piezoelectric Micromachined Ultrasound Transducers (pMUT) on silicon substrates is presented. Piezoelectric elements are formed by deposition of PZT $\left(\left(\mathrm{PbZr}_{\mathrm{x}} \mathrm{Ti}_{1-\mathrm{x}}\right) \mathrm{O}_{3}\right)$ into etched features of the silicon substrate such that the depth of these features determine the element thickness and hence the resonance frequency. The process leaves a near planar surface which is ideal for further wafer level processing such as top electrode and interconnect formation. A fabricated single element is characterized by pulse echo response.
\end{abstract}

PZT; thick film, pMUT

\section{INTRODUCTION}

For a number of years high frequency ultrasonic imaging has been based on single element transducers or annular arrays. The earliest high frequency ultrasound devices were based on PVDF [1] and more recently ceramic high frequency ultrasound transducers have emerged [2]. For many purposes single element transducers or annular arrays are excellent, however in order to obtain a full image they must be mechanically scanned. For many medical diagnostics cases such as intravenous investigations this is problematic and the beam steering ability of array based transducers is necessary. Fabrication of high frequency transducer arrays are however difficult but in this work we present a new method to fabricate high frequency PZT based linear array transducers.

The transducers are fabricated on silicon wafers by integration of ceramic thick film deposition technology with silicon micromachining [3]. This integration makes it possible to define the lateral element dimension and position with UV photolithography resolution. Piezoelectric elements are created by first etching out the desired element layout into a silicon wafer and subsequently filling the etched structure with PZT. In this way the element thickness, $t$, and hence the resonance frequency is defined by the silicon etch which is easy to control.

\section{TRANSDUCER GEOMETRY}

For this work [100] oriented silicon wafers are used. An anisotropic etchant, $\mathrm{KOH}$, is used to create the structure in the wafer. $\mathrm{KOH}$ has a very low etch rate in the [111] direction and thus the etched structure has an angle given by the angle between the [100] and [111] silicon planes as illustrated in Fig. 1. This angle is $\theta=54.7^{\circ}$. For an array of elements this puts a constraint on the minimum kerf that can be obtained. The geometric relation between the total element width, $w$, the depth of the etched structure, $d$, and half of the kerf, $k_{1 / 2}$, is seen in the figure. The active element width covered by the top electrode is given as $x$. It should be noted that due to contraction during sintering the element thickness, $t$, is only 80$90 \%$ of the etched depth, $d$. As the element thickness, and hence the frequency, is related to the kerf we can derive the minimum obtainable element spacing, or pitch, in terms of $\lambda$, the wavelength in water. Simple geometry relates the total width, $w$, to the active element width, $x$, and depth as

$$
w=x+2 \frac{d}{\tan \theta} .
$$

From this we calculate the minimum pitch, $n$, in terms of $\lambda$ as a function of $d$ and $x$

$$
n=\frac{c_{P Z T}}{c_{\text {water }}}\left(\frac{1}{\tan \theta}+\frac{x}{2 d}\right) .
$$

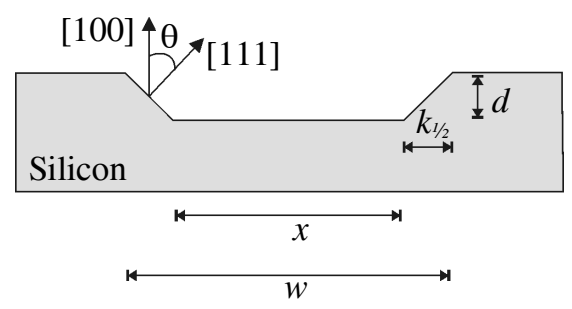

Figure 1. Schematic illustration of the structure etched in [100] oriented Si for a single piezoelectric element. 


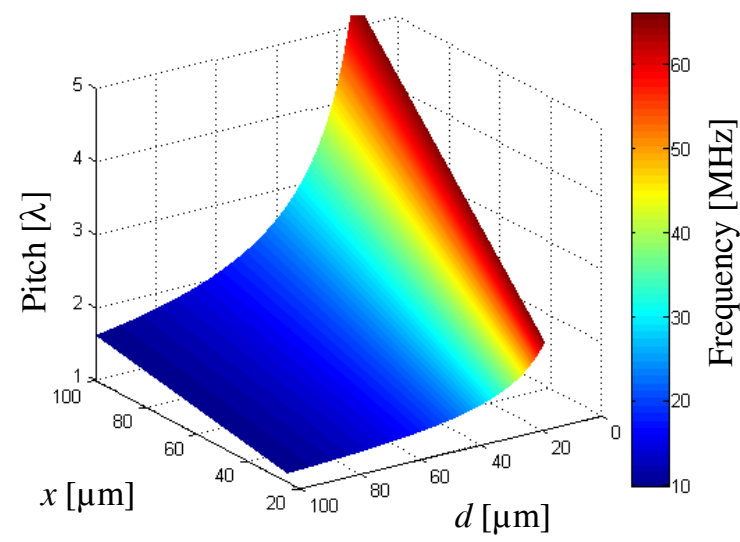

Figure 2. Plot showing the pitch as a function of active element width, $x$, and the etched depth, $d$. The color indicates the resonance frequency.

This minimum pitch as a function of etch depth, $d$, and active element width, $x$, is seen in Fig. 2. As seen it is only possible to obtain $\lambda$ pitch for quite small elements with an active width of around $x=20 \mu \mathrm{m}$. For larger element sizes or frequencies above $25 \mathrm{MHz}$ it is necessary to revert to $1.5 \lambda$ pitch or even higher.

\section{FABRICATION}

\section{A. Fabrication prior to PZT deposition}

The fabrication technique is illustrated in Fig. 3. For fabrication a standard $100 \mathrm{~mm}$ silicon wafer is used. A $500 \mathrm{~nm}$ silicon oxide film is grown and the desired element layout is patterned with UV photolithography and etched with buffered hydrofluoric acid. Subsequently the silicon oxide layer is used as an etch mask in a $\mathrm{KOH}$ etch. The etch rate in silicon is 1.3 $\mu \mathrm{m} / \mathrm{min}$ and the etch is terminated when the desired depth is reached. The etched structure will subsequently serve as moulds for the PZT deposition.

a)

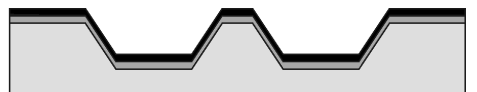

b)

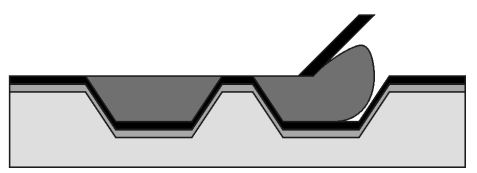

c)

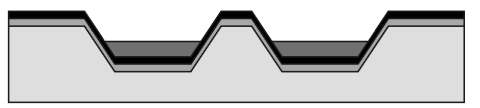

d)

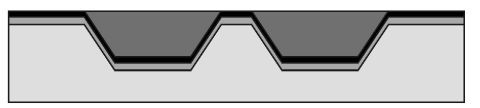

$\square \mathrm{Si}$

$\square \mathrm{SiO}_{2}$

$\square$ PZT

Metal

Figure 3. Schematic illustration of the first part of the fabrication process including the PZT deposition.

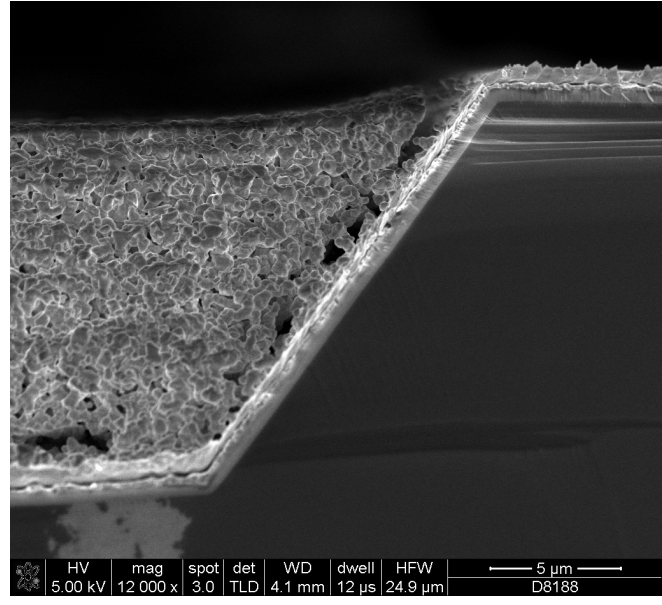

Figure 4. Cross sectional SEM micrograph of the etched structure filled with PZT. Due to the contraction during sintering the PZT has detached from the sloping silicon side leaving a free standing piezoelectric element.

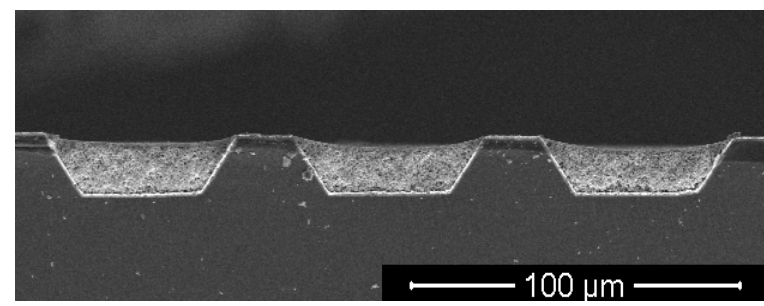

Figure 5. Cross sectional SEM micrograph showing three transducer elements with a thickness of $15 \mu \mathrm{m}$ and a pitch of $75 \mu \mathrm{m}$.

After $\mathrm{KOH}$ etching a new $500 \mathrm{~nm}$ silicon oxide is grown and a $50 \mathrm{~nm} \mathrm{Ti}$ and $500 \mathrm{~nm}$ Pt bottom electrode is deposited by e-beam evaporation in an Alcatel SCM600, see Fig 3(a). The silicon oxide layer and bottom electrode serve as a diffusion barrier layer between the PZT film and the silicon substrate. This is necessary to prevent interdiffusion of $\mathrm{Si}$ and $\mathrm{Pb}$ which will otherwise degrade the piezoelectric coefficients [4].

\section{B. PZT deposition}

PZT is deposited into the $\mathrm{KOH}$ etched structure using a modified Ferroperm PZ26 paste. This has been specifically optimized for screen printing onto silicon substrates by addition of sintering agents that lowers the necessary sintering temperature. The paste is evenly distributed over the wafer and into the etched structure, after which excess paste is removed using a plastic scraper, see Fig. 3(b). Subsequently the paste is dried so that the organic vehicle evaporates and the PZT powder sediments in the bottom of the structure, see Fig. 3(c). This procedure is repeated until the structures is completely filled with PZT and the wafer is annealed at $850^{\circ} \mathrm{C}$ for one hour to sinter the PZT, Fig. 3(d). A cross sectional SEM micrograph of a single element is seen in Fig. 4 and in Fig. 5 three $15 \mu \mathrm{m}$ thick elements with a pitch of $75 \mu \mathrm{m}$ are seen as an example of the possibilities this technique offers.

\section{Top electrode formation}

After application of PZT the top electrode is deposited. It has proven difficult to wirebond to thin metal films on the 
rough PZT surface so it is necessary to create top electrode bonding pads outside the PZT area. The SEM micrograph in Fig. 4 shows the edge of the $\mathrm{KOH}$ etched structure filled with PZT. Due to the shrinkage during sintering a gap has formed between the sloped silicon wall and the PZT. Thus the top electrode has to cross over this gap. A solution with a polymer bridge is employed.

The procedure is outlined in Fig. 6 and is a continuation of the fabrication described earlier and illustrated in Fig. 3. The first step is to define the polymer bridge for the top electrode. The polymer used is a $10 \mu \mathrm{m}$ thick layer of AZ 4265 positive tone photoresist. It is patterned by UV photolithography and after development the sidewalls of the resist are nearly vertical, Fig. 6(b). The polymer is hard baked at $250^{\circ} \mathrm{C}$ for $30 \mathrm{~min}$. During this baking step the polymer flows and the result is a sloped sidewall that can easily be covered with an e-beam evaporated top electrode, Fig. 6(c). Furthermore the hard baking makes the polymer resistant against acetone which is critical for the definition of the top electrode. The top electrode is made by e-beam evaporation of $500 \mathrm{~nm} \mathrm{Al}$ using a lift off process using acetone to dissolve the resist, Fig. 6(d). An optical microscope image of this construction is seen in Fig. 7. The top part of eight elements are seen in the image, also the top electrode construction is seen. Every second element has a wire contacting a bond pad in the top of the elements and every other second element has a similar construction in the bottom outside of the image. The bond pads are placed on the $10 \mu \mathrm{m}$ thick photoresist layer but due to a low dielectric constant of 3.5 of the polymer, this does not induce significant capacitances.

a)

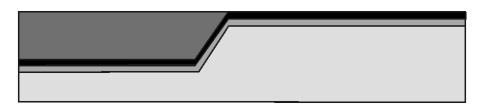

b)

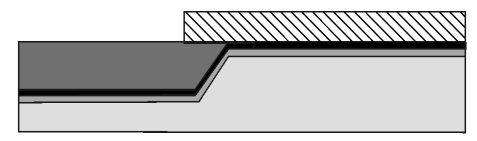

c)

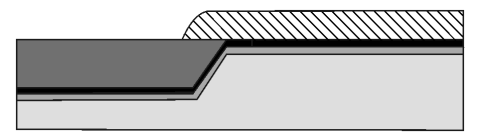

d)

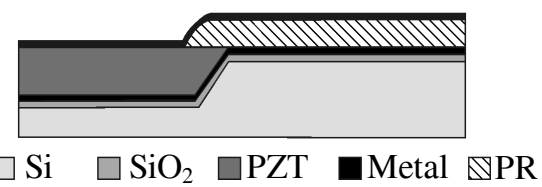

Figure 6. Schematic illustration of the second part of the fabrication process where the top electrode is deposited.

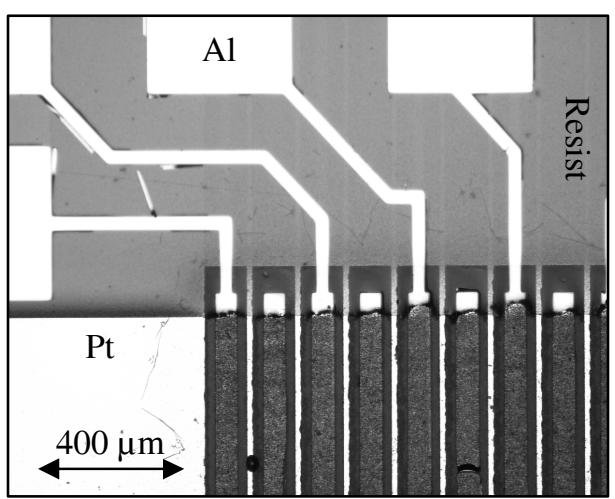

Figure 7. Optical microscope image showing part of a linear array. The top of each element is covered by the polymer bridge as illustrated in Fig. 6. Also the top $\mathrm{Al}$ and the bottom Pt electrodes are seen.

\section{CHARACTERIZATION}

The element to element uniformity is investigated by the use of a Tencor P-1 stylus profiler. A scan of an 8 element array is seen in Fig. 8. The etched depth in this case is $54 \mu \mathrm{m}$ and thus the baseline of the scan is set to $54 \mu \mathrm{m}$ as seen in the figure. Due to contraction during sintering of the PZT, the elements do not have the full height of the etched structure and the thickness of each element has a minimum at the center of the element. From the profile scan it is concluded that the mean center element thickness is $47.8 \mu \mathrm{m}$ with a standard deviation of $0.45 \mu \mathrm{m}$. This corresponds to an element to element thickness deviation of $1 \%$.

In order to investigate the ability to emit and receive ultrasound a pulse echo setup is used. The setup consists of a JSR Ultrasonics DPR500 Pulser/Reciever with a RP-H2 remote pulser. For data acquisition an Agilent Infinium DSO8064A is used. The transducer is placed in a water tank $18 \mathrm{~mm}$ from a metal reflector. For this test no matching layer or backing layers have been applied. A short pulse is applied to the transducer and the recorded response is seen in Fig. 9. The corresponding spectrum is seen in Fig. 10. The absence of a backing layer is apparent from both figures as the transducer shows a low bandwidth signal with peaks spaced $7.3 \mathrm{MHz}$

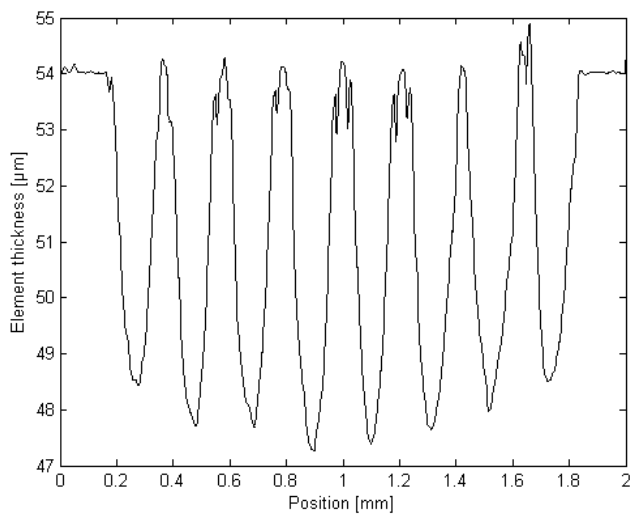

Figure 8. Stylus profile scan of an 8 element linear array. The etched depth is $54 \mu \mathrm{m}$ and the mean center element thickness is $47.8 \mu \mathrm{m}$. 
apart. This resonance is caused by the silicon substrate which has a thickness of about $575 \mu \mathrm{m}$. With a sound velocity of 8400 $\mathrm{m} / \mathrm{s}$ in silicon this corresponds to a resonance frequency of 7.3 MHz.

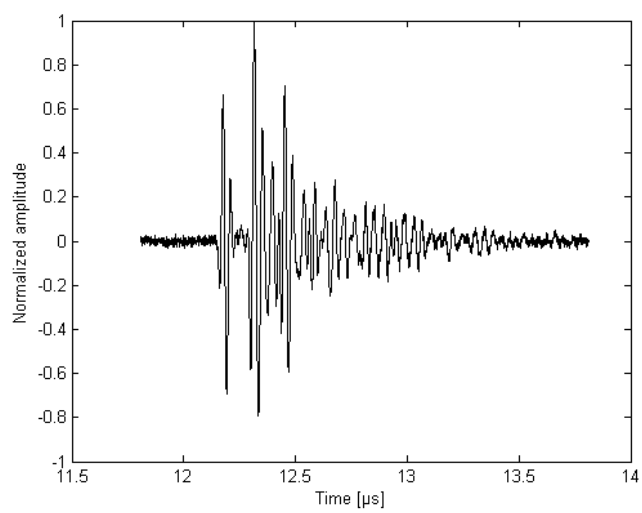

Figure 9. Normalized pulse echo response from a single element of the fabricated transducer array. Neither matching layers or backing layers were applied.

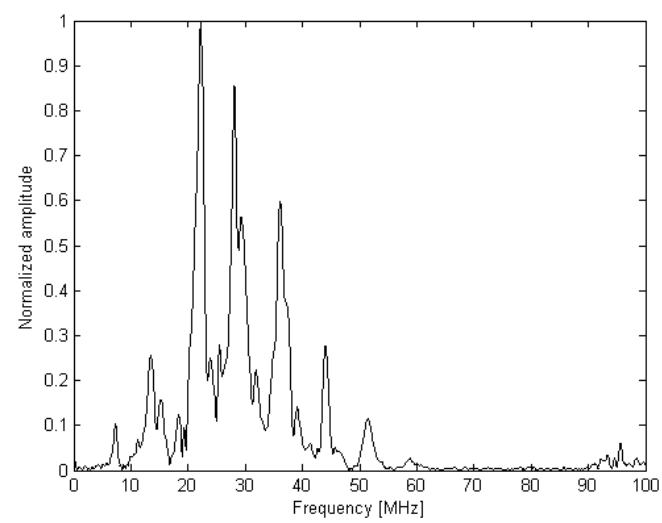

Figure 10. Pulse spectrum showing resonances spaced 7.3 MHz from each other. These resonance are caused by ringing in the silicon substrate.

\section{CONCLUSION}

The fabrication technique described in this paper offers rapid and cheap production of high frequency piezoelectric micromachined ultrasound transducers on silicon substrates. The process yields elements that has a good element to element thickness uniformity as the thickness is mainly defined by the silicon etch which is easy to control.

The use of a silicon substrate and an anisotropic etchant provides a very cheap base for fabrication of these elements. However, the characteristic angle of the $\mathrm{KOH}$ etch puts a constraint on the minimum pitch that can be obtained. Thus it is only possible to fabricate arrays with $\lambda$ pitch with frequencies below $25 \mathrm{MHz}$. For higher frequencies the pitch will be larger than $\lambda$.

The polymer bridge technique described in the fabrication process has proven to be a good way of routing the top electrode away from the piezoelectric elements for electrical connection. The polymer has a dielectric constant of 3.5 and thus the construction does not give rise to significant additional capacitances. Furthermore the polymer layer has proven able to withstand electric fields of up to $40 \mathrm{~V} / \mu \mathrm{m}$, which is more than sufficient for both polarization and pulsing of the elements.

Pulse echo measurements performed on single elements demonstrate the ability to both emit and receive ultrasound waves. The quality of the response and the spectrum are however not optimal as the signal is seen to have a quite low bandwidth and is dominated by ringing in the wafer. This is due to the absence of a backing layer in the first prototype of transducers produced of this type.

\section{REFERENCES}

[1] M. D. Sherar, F. S. Foster, The design and fabrication of high-frequency polyvinylidene flouride transducers," Ultrason. Imaging, vol. 11, pp. 7594, 1989

[2] G. R. Lockwood, D. H. Turnbull, F. S. Foster, "Fabrication of high frequency spherically shaped ceramic transducers," IEEE Trans. Ultrason. Ferroelect. Freq. Contr., vol. 41, pp. 231-235, 1994

[3] R. Lou-Moeller, C. C. Hindrichsen, L. H. Thamdrup, T. Bove, E. Ringgaard, A. F. Pedersen, Erik V. Thomsen, "Screen-printed piezoceramic thick films for miniturised devices," J. of Electroceramics, vol. 19, pp. 333-338, 2007

[4] C. C. Hindrichsen, T. Pedersen, E. V. Thomsen, K. Hansen, R. LouMoeller, "Investigation of top/bottom electrode and diffusion barrier layer for PZT thick film MEMS sensors," Ferroelectrics, in press 